\section{Y-12}

NATIONAL SECURITY COMPLEX

\section{Boron-Loaded Silicone Rubber Scintillators}

\author{
Z. W. Bell \\ Technology Development \\ Manufacturing Systems \\ L. Maya \\ G. M. Brown \\ F. V. Sloop, Jr. \\ Oak Ridge National Laboratory
}

Date of Issue: May 12, 2003 


\section{DISCLAIMER}

This report was prepared as an account of work sponsored by an agency of the United States Government. Neither the United States Government nor any agency thereof, nor any of their employees, makes any warranty, express or implied, or assumes any legal liability or responsibility for the accuracy, completeness, or usefulness of any information, apparatus, product, or process disclosed, or represents that its use would not infringe privately owned rights. Reference herein to any specific commercial product, process, or service by trade name, trademark, manufacturer, or otherwise, does not necessarily constitute or imply its endorsement, recommendation, or favoring by the United States Government or any agency thereof. The views and opinions of authors expressed herein do not necessarily state or reflect those of the United States Government or any agency thereof. 


\title{
Boron-Loaded Silicone Rubber Scintillators
}

\author{
Zane W. Bell \\ Technology Development \\ Manufacturing Systems
}

\author{
L. Maya \\ G. M. Brown \\ F. V. Sloop, Jr. \\ Oak Ridge National Laboratory
}

Date of Issue: May 12, 2003

\author{
Prepared by the \\ Y-12 National Security Complex \\ P. O. Box 2009, \\ Oak Ridge, Tennessee 37831-8169 \\ managed by \\ BWXT Y-12 L.L.C. \\ for the \\ U.S. DEPARTMENT OF ENERGY \\ under contract DE-AC05-00OR-22800
}




\author{
Boron-Loaded Silicone Rubber Scintillators \\ Z. W. Bell \\ Y-12 National Security Complex \\ L. Maya, G. M. Brown, and F. V. Sloop, Jr. \\ Oak Ridge National Laboratory
}

Abstract- Silicone rubber received attention as an alternative to polyvinyltoluene in applications in which the scintillator is exposed to high doses because of the increased resistance of the rubber to the formation of blueabsorbing color centers. Work by Bowen, et al., and Harmon, et al., demonstrated their properties under gamma/xray irradiation, and Bell, et al. have shown their response to thermal neutrons. This last work, however, provided an example of a silicone in which both the boron and the scintillator were contained in the rubber as solutes, a formulation which led to the precipitation of solids and sublimation of the boron component. In the present work we describe a scintillator in which the boron is chemically bonded to the siloxane and so avoids the problem of precipitation and loss of boron to sublimation. Material containing up to $18 \%$ boron, by weight, was prepared, mounted on photomultipliers, and exposed to both neutron and gamma fluxes. Pulse height spectra showing the neutron and photon response were obtained, and although the light output was found to be much poorer than from samples in which boron was dissolved, the higher boron concentrations enabled essentially $100 \%$ neutron absorption in only a few millimeters' thickness of rubber.

\title{
I. Introduction
}

Silicone rubbers have a long history. Roff [1] reports that although silicon esters were prepared in 1846, and organo-silicon materials were prepared around 1870, major research and commercial development activities with this material did not begin until the 1930s. Around 1990, with the proposal of larger high-energy physics accelerators, silicones were investigated [2], [3] as a substitute for polyvinyltoluene in scintillators because the latter material had been observed to yellow after absorbing megarad doses. In addition, silicones, being elastic, are not prone to crazing and cracking because of residual stresses introduced during curing (in fact, silicones cure at or only slightly above room-temperature).

Dissolution of carborane into silicone rubber has been reported previously [4] with good results. The resulting material was sufficiently clear that centimeter-thick disks could be used effectively as thermal neutron detectors. The solubility of carborane in silicone, however, limited the amount of boron that could be put into the rubber, and, as part of the present work, it was found that the volatility of carborane coupled with the relative openness of the rubber promoted sublimation of the carborane to the point of rendering the rubber insensitive to thermal neutrons. Consequently an effort was launched to attach boron compounds to siloxane. This paper reports the detection of neutrons with silicone rubber with boron bonded to the siloxane.

\section{Measurements}

Samples of silicone rubber were prepared by catalyzing a two-component liquid mixture one component of which contained the boron, the second provided cross-linking, and into which mixture diphenyl oxazole (PPO) and triphenyl pyrazoline (TPY). Previous work [4] had shown that siloxane with PPO at $1.5 \%$ and TPY at $0.15 \%$ yielded a blue-emitting scintillator, and that was done in the present work as well. Disks were polymerized in glass vials, which had been coated with clear silicone grease as a release agent, and although the rubber disks were easily freed from the vials, it was apparent that diffusion of the grease into the samples had occurred, resulting in a cloudy surface where the rubber was in contact with the glass and cloudy wisps within the disks. The free top surface, however, was clear and, after trimming the small lip of the meniscus, could be coupled to a Hamamatsu R1947 photomultiplier with optical grease.

Although the unpolymerized liquid was water clear, after polymerization the resulting monolith had a yellowish cast. It has not yet been determined if this is the natural color of the rubber or a result of an unknown reaction between the fluors and the silicone fluids. In any event, it was obvious that there would be little use in using specimens much thicker than $6 \mathrm{~mm}$, since the poor surfaces, interior cloudiness, and color could reasonably be expected to degrade light collection significantly. 


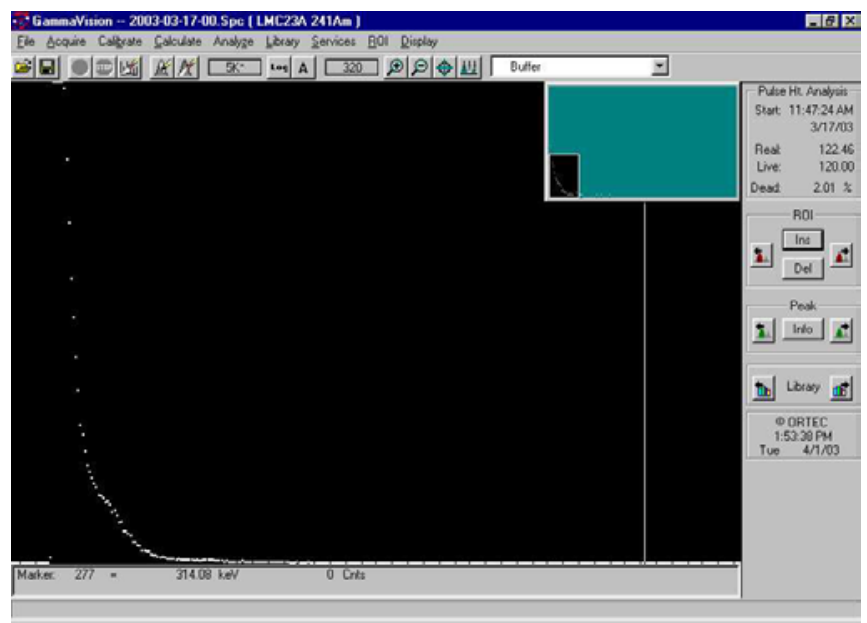

Figure 1. Response of $18 \%$ sample to $60 \mathrm{keV}$ gamma rays.

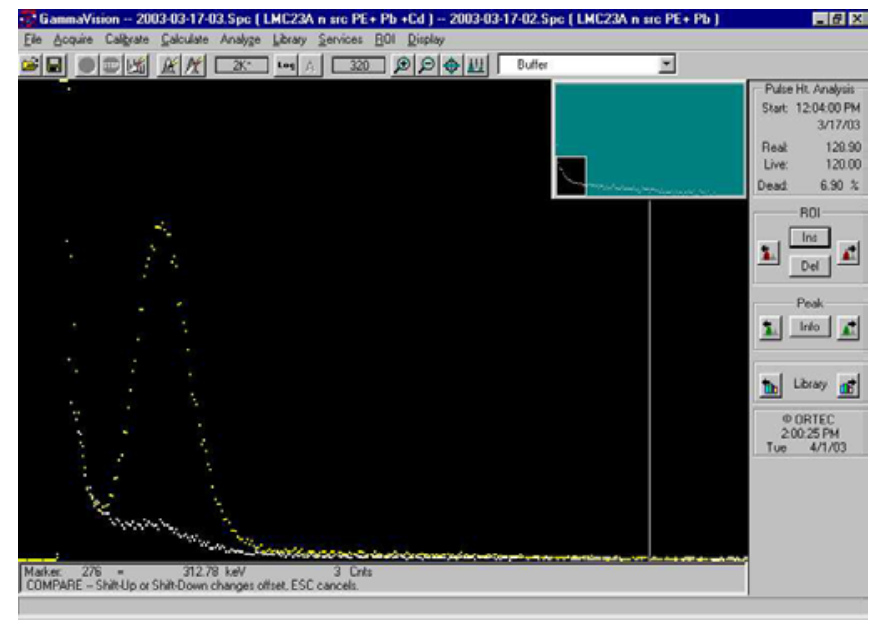

Figure 2. Response of $18 \%$ sample to neutrons.
Samples of rubber with $7 \%, 10 \%$, and $18 \%$ boron, by weight, were prepared as disks $2.5 \mathrm{~cm}$ in diameter and either $3 \mathrm{~mm}$ or $6 \mathrm{~mm}$ thick. The response of an $18 \%, 3 \mathrm{~mm}$ disk to $60 \mathrm{keV}$ gamma rays from ${ }^{241} \mathrm{Am}$ is shown in Figure 1. Only a hint of a photopeak is evident in the shoulder. This is not completely unexpected not only because of the relatively poor optical quality of the sample, but because the mean free path for photoelectric absorption much longer than $3 \mathrm{~mm}$.

However, the response of this same sample to neutrons is apparent in Figure 2. The spectrum containing the peak corresponding to the deposition of $2.35 \mathrm{MeV}$ by the products of the ${ }^{10} \mathrm{~B}(\mathrm{n}, \alpha)^{7} \mathrm{Li}$ reaction was obtained with the detector inserted for two minutes into a thermalized AmLi source producing approximately $100 \mathrm{n} / \mathrm{cm}^{2} / \mathrm{s}$ at the detector The spectrum below it, shows the effect of placing a $\mathrm{Cd}$ cup over the detector. The thermal peak vanishes, except for the events caused by leakage and the few fast neutrons present. Careful examination of Figures 1 and 2 show that the pulse height corresponding to the neutron peak is approximately twice that corresponding to the 60 $\mathrm{keV}$ gamma rays, consistent with what might be expected from heavy ions.

\section{Conclusions}

The operation of a boron-loaded silicone rubber scintillator has been demonstrated. Although not completely insensitive to gamma rays, the high boron content enables the fabrication of an efficient

neutron detector while minimizing gamma sensitivity. In addition, since the boron content can be varied, it should be possible to devise detecting media with gamma sensitivity tailored to a specific task. Since this material is still new, it will be necessary to study its stability over long periods of time to verify that there is no loss of boron. It remains to improve the optical quality of the material, and to improve its brightness by the addition of phenyl rings at the expense of methyl groups.

Acknowledgement

This work supported by the U.S. Department of Energy under contracts DE-AC-05-00OR22800 (Y-12 National Security Complex), and DE-AC05-96OR22464 (Oak Ridge National Laboratory).

1. W. J. Roff, Fibres, Plastics, and Rubbers, pp. 236 - 242, Academic Press, New York, 1956.

2. M. Bowen, S. Majewski, D. Pettey, J. Walker, R. Wojcik, and C. Zorn, IEEE Trans. on Nucl. Sci., 36 No. 1, p. $562,1989$.

3. J. Harmon, J. Gaynor, V. Feygelman and J. Walker, Nucl. Inst. Meth. in Phys. Res. B53, p. 309, 1991.

4. Zane W. Bell, Gilbert M. Brown, C. H. Ho, and Frederick V. Sloop, Jr., in X-Ray and Gamma-Ray Detectors and Applications IV, Ralph B. James, Larry A. Franks, Arnold Burger, Edwin M. Westbrook, Roger D. Hurst, Eds., Proceedings of SPIE, Vol. 4784 (2002) 150. 